BIOMEDICA

Vol. 8 Nos. 3 y 4 - 1988

\title{
NORMAS DE BIOSEGURIDAD EN EL LABORATORIO
}

\author{
IGNACIO ARBOLEDA PERDOMO 1
}

La transmisión de enfermedades infectocontagiosas por contaminación accidental en el laboratorio suele ser poco probable si las muestras se manipulan con precaución. El riesgo más alto está en la contaminación con sangre o fluidos de pacientes con SIDA, hepatitis A o B, polio, rabia, fiebre amarilla, malaria, etc. Los errores más frecuentes en la manipulación de las muestras, que colocan al personal en mayor riesgo de contaminación accidental, consisten en: a) que el profesional de laboratorio toma extremas precauciones en la manipulación de la muestra solamente cuando sabe que el paciente tiene alguna de estas enfermedades infectocontagiosas. Para saberlo debió, la mayoría de veces, realizar alguna prueba de laboratorio con anterioridad y en esa ocasión no tomó las suficientes precauciones. b) consiste en tomar precauciones en la manipulación de las muestras, cuando éstas van a la Unidad de Seroinmunología, pero no cuando van a Química Clínica o Hematología siendo las muestras exactamente de los mismos pacientes.

Por esto "TODA MUESTRA DE LABORATORIO ES POTENCIALMENTE TRANSMISORA DE ENFERMEDADES Y DEBE MANEJARSE COMO TAL”.

A continuación se consignan las recomendaciones básicas para prevenir la contaminación accidental del personal del laboratorio, por el manejo de sangre y otros fluidos biológicos en los análisis clínicos.

- Utilice siempre blusa para el trabajo en el laboratorio.

- Use guantes desechables de cirugía para tomar cualquier muestra.

- Desinfecte con alcohol yodado la zona de venopunción.
- Si el trabajador del laboratorio tiene heridas o alguna escoriación en la piel, debe cubrirla antes de empezar su labor.

- El sistema para toma de muestras por venopunción, por su bajo riesgo de contaminación, es el de tubos al vacío; la manipulación del especimen es mínima. Dado que, aparentemente, este procedimiento es costoso y no está al alcance de todos los laboratorios. Debe exigirse, sin embargo, el uso de jeringas y agujas desechables.

- No inserte nuevamente la funda de la aguja después de haber tomado muestra de sangre, SE AUMENTA EL RIESGO DE PUNCION ACCIDENTAL; desempate la aguja de la jeringa y colóquela dentro de una lata de cerveza o gaseosa, que contenga de 50 a 70 $\mathrm{ml}$ de solución de: hipoclorito de sodio al 3\% (decol, clorox,* etc).

- Vierta el contenido de la jeringa en el tubo o frasco apropiado para el examen y ciérrelo con su respectivo tapón. NUNCA DEJE LAS MUESTRAS ABIERTAS.

- Transporte las muestras con sumo cuidado, manteniéndolas siempre tapadas.

- La ruptura de los tubos en la centrífuga, es el más frecuente de los accidentes en el laboratorio, para minimizar el riesgo de contaminación por salpicaduras se deben balancear los tubos en la centrífuga por peso y no por volumen.

- "NUNCA PIPETEE CON LA BOCA NINGUN ESPECIMEN DE LABORATORIO"; use micro pipetas con puntas desechables, peras succionadoras, ayudantes de pipetas o goteros de caucho.

\footnotetext{
1 Bacteriólogo, Jefe del Laboratorio de Química Clínica, Coordinador Nacional del Programa de Control de Bancos de Sangre. INS. Bogotá *Nombre, comercial del producto.
} 
- NO COMA, BEBA, FUME O SE APLIQUE COSMETICOS EN EL LABORATORIO.

- Siempre que manipule sangre, suero u otro material biológico, cualquiera sea su procedencia, "USE GUANTES DE CAUCHO".

- Al terminar el trabajo lávese bien las manos con abundante agua y jabón, lo mismo cuando vaya a ingerir alimentos.

- Evite contestar al teléfono, abrir puertas, neveras, congeladores $\mathrm{u}$ otros elementos de uso común en el laboratorio cuando esté manipulando suero, sangre u otro especimen biológico. Planee adecuadamente su trabajo así como los reactivos y materiales que requiere durante los procedimientos analíticos.

- Limpie adecuadamente el mesón de trabajo con solución al 3\% de hipoclorito de sodio (decol, clorox) al empezar y al terminar su trabajo.

- Descarte los materiales desechables tales como jeringas, guantes, puntas de micropipetas, cubetas plásticas, etc. en una solución al 3\% de hipoclorito de sodio y destrúyalas por incineración. NUNCA REUTILICE EL MATERIAL DESECHABLE QUE HA ESTADO EN CONTACTO CON FLUIDOS BIOLOGICOS DE PACIENTES.
- Elimine en solución de hipoclorito de sodio al 3\% los sobrantes de suero, plasma, sangre y demás fluidos biológicos.

- El material de laboratorio reutilizable de vidrio o plástico, se debe colocar en solución al 3\% de hipoclorito de sodio mínimo por 2 horas antes de pasarlos a lavado.

- Las agujas desechables que se han recogido en las latas de cerveza o gaseosa, deben destruirse por incineración. NUNCA ARROJE AGUJAS A LA BASURA.

- RECUERDE QUE LAS NORMAS NO EVITAN UN ACCIDENTE, LO PREVIENEN. LO UNICO QUE LO EVITA ES LA RESPONSABILIDAD EN EL TRABAJO.

\section{BIBLIOGRAFIA}

1. Guzmán M, Ibagón $H$, Bernal M. Precauciones y recomendaciones para personal con riesgo accidental. Serie de notas de informes técnicos No. 16. INS. 1988.

2. Teasdale, E. Handling blood and other human specimens. Ocupational Health, February, 1988.

3. Rodríguez, M. Normas de Garantía de Calidad en el Laboratorio Comunicación Verbal. 1988.

4. Arboleda, I. Manual Operativo de Bancos de Sangre. Serie publicaciones científicas No. 16. INS. 1989. 